\title{
The Allele 2 of the VNTR Polymorphism in the Gene That Encodes a Natural Inhibitor of IL-1ß, IL-1RA Is Favorably Associated With Chronic Otitis Media
}

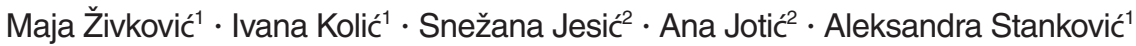 \\ ${ }^{1}$ Vinca Institute of Nuclear Sciences, Laboratory for Radiobiology and Molecular Genetics, University of Belgrade, Belgrade; ${ }^{2}$ Clinic of \\ Otorhinolaryngology and Maxillofacial Surgery, Clinical Centre of Serbia, University of Belgrade School of Medicine, Belgrade, Serbia
}

Objectives. Chronic otitis media (COM) is followed by irreversible tissue damage and destruction of the middle ear structures, with the possibility of complications under the maintenance of inflammation. Inflammatory mediators such as cytokines play a crucial role in the initial stage of inflammation. The aim of this study was to evaluate the association of the polymorphisms in two innate immunity/inflammation cascade genes from interleukin-1 (IL-1) gene cluster with COM with regard to cholesteatoma.

Methods. In the cross-sectional case-control study, DNA samples were collected from 189 patients with COM and 119 controls from a population of Serbia. The $+3953 \mathrm{C} / \mathrm{T}$ (rs1143634), TaqI polymorphism in interleukin-1 beta (IL-1 $\beta$ ) gene and $86 \mathrm{bp}$ variable number tandem repeat (VNTR, rs2234663) polymorphism in the IL-1 receptor antagonist (IL-1RA) gene were analyzed by polymerase chain reaction.

Results. The IL-1 $\beta$ TaqI polymorphism was not significantly different in patients compared with the control group. The significant difference between patients and controls was observed for both, genotype and allele frequencies of IL-1RA VNTR polymorphism (chi-square $P<0.01$ ). We found that carriers of IL-1RA allele 2 (odds ratio, 0.47 ; $95 \%$ confidence interval, 0.29 to $0.76 ; P=0.004$ ) have a favorable association with COM, using multivariate logistic analysis that included both polymorphisms, age and sex. The IL-1RA allele frequency distribution was significantly different with regard to cholesteatoma.

Conclusion. The carriers of allele 2 of VNTR IL-1RA polymorphism had a decreased odds ratio for COM, which is in agreement with findings in other inflammatory disease and its previous association with higher IL-1RA levels. Possible down-regulation of IL-1 mediated proinflammatory signaling pathways via IL-1RA in COM as well as results of our study should be further investigated and replicated.

Keywords. Interleukin-1Beta; Interleukin-1 Receptor Antagonist; Genetic Polymorphism; Otitis Media; Cholesteatoma

\section{INTRODUCTION}

Otitis media $(\mathrm{OM})$ is a worldwide health problem with high prevalence, which consumes many medical resources. It is a

\footnotetext{
- Received August 21, 2017

Revised January 5, 2018

Accepted January 5, 2018

- Corresponding author: Aleksandra Stanković

Vinca Institute of Nuclear Sciences, Laboratory for Radiobiology and

Molecular Genetics, University of Belgrade, Mike Petrovica Alasa 12-14, 11001 Belgrade, Serbia

Tel: +381-113408566, Fax: +381-116447485

E-mail: alexas@vinca.rs
}

multifactorial disorder in which bacterial infection plays an important role. Chronic otitis media (COM) is followed by irreversible tissue damage and destruction of the middle ear structures, with the possibility of complications under the maintenance of inflammation. To date, only few genetic studies have been performed in OM, but mostly in COM with effusion and recurrent $\mathrm{OM}(\mathrm{ROM})$, and the results have been ambiguous [1-5]. Inflammatory mediators such as cytokines play a crucial role in the initial stage of inflammation [1] caused by bacteria [6-8] and their role in OM have been suggested $[9,10]$. The interleukin- 1 beta (IL-1 $\beta$ ) is a mediator of both bacterial and viral OM and has influence on many different target cells, thus it stimulates proin-

Copyright @ 2018 by Korean Society of Otorhinolaryngology-Head and Neck Surgery.

This is an open-access article distributed under the terms of the Creative Commons Attribution Non-Commercial License (http://creativecommons.org/licenses/by-nc/4.0)

which permits unrestricted non-commercial use, distribution, and reproduction in any medium, provided the original work is properly cited. 
flammatory network in the middle ear and could induce activation and proliferation of fibroblast and growth of osteoclasts in the middle ear possibly leading to fibrosis and bone erosion $[1,11]$. Cholesteatomas, the epidermal lesions in the middle ear that lead to erosion of bones, are commonly associated with $\mathrm{ROM}$ and often contains bacteria. It was recently shown that inflammation and innate immunity system play an important role in cholesteatomas, as well $[12,13]$.

The number of studies revealed the association of IL- 1 gene cluster with a predisposition to certain inflammatory diseases, but only a few had been performed in OM $[14,15]$. The genetic variant +3953 (rs1143634) in IL-1 $\beta$ has been suggested to influence production of IL-1 $\beta$ protein [16] while the variable number tandem repeat (VNTR) variant (rs2234663) in anti-inflammatory IL-1 receptor antagonist (IL-1RA, also called IL-1RN) has been proposed to influence expression of IL-1RA protein [17].

The aim of this study was to evaluate the association of the polymorphisms in two innate immunity/inflammation cascade genes from a single cluster (IL-1 $\beta+3953 \mathrm{C} / \mathrm{T}$ and IL-1RA $86 \mathrm{bp}$ VNTR) with COM with regard to cholesteatoma. Bacterial flora and basic biochemical parameters were also analyzed with regard to the presence of cholesteatoma and genotypes of investigated polymorphisms.

\section{MATERIALS AND METHODS}

\section{Subjects}

This cross-sectional case-control study was approved by the Ethics Committee of the Clinical Center of Serbia (approval No. 29/VI-15). All participants (or parents of children) gave their signed informed consent for participation in the study.

All of the patients underwent surgery due to the symptoms of chronic middle ear disease. The 189 consecutive patients with COM without effusion were collected at the Clinic of Otorhinolaryngology and Maxillofacial Surgery, Clinical Centre of Serbia, Belgrade from 2011 to 2013 to participate in the study. The blood samples for genetic analysis were collected prior middle ear surgery. The children suspected of having head and neck anomalies, systemic disease or congenital or acquired immunodeficiency were excluded from the study. In order to evaluate the most common etiological agent in patients with multiple bacteria in cultures were excluded from the study. The patient

\section{H I G H L I G H T S}

- The allele 2 of interleukin-1 receptor antagonist variable number tandem repeat is favorably associated with chronic otitis media.

- The interleukin-1 receptor antagonist allele frequencies were significantly different with regard to cholesteatoma. group consisted of 34 children (aged between 2 and 18 years, mostly $>5$ years old) and 155 adults (aged $41 \pm 19$ years). In children, male sex was predominantly present $(61.76 \%)$ while in adults, females predominated $(54.36 \%)$. In total, there were $47.08 \%$ males and $52.92 \%$ females in the patient group. According to the ear pathology group consisted of patients with nonsuppurative COM with tympanic membrane retraction without cholesteatoma, patients with suppurative COM and tympanic membrane perforation and patients with COM with cholesteatoma.

From the adults undergoing annual medical check-up at Occupational Medical Centers, Belgrade, Serbia, who underwent clinical and biochemical examination, 119 (aged $41 \pm 15$ years) that were without previous history of COM and allergies and evidence of any chronic inflammatory disease such as, rheumatoid arthritis, systemic lupus or allergies, asthma, inflammatory bowel disease and Crohn disease, renal failure or diabetes mellitus were recruited as controls. In controls otomicroscopy, pure tone audiometry and tympanometry were done. The appearance of the tympanic membrane under a microscope was uneventful, audiogram showed normal hearing and type A tympanogram the proper mobility of the tympanic membrane. The results of these examinations have pointed to a healthy middle ear.

Diagnosis of COM was established by otomicroscopy, tympanometry in retracted tympanic membrane, pure tone audiometry in patients over five or objective audiometry in younger children. Computed tomography of temporal bone was performed in cholesteatoma patients. Patients with tympanic membrane retraction (COM non-suppurativa) underwent surgery using different techniques depending of retractions' stage and auditory ossicle conditions. Retracted tympanic membranes were classified according to the Erasmus classification for pars tensa retraction and Tos classification for attic retractions $[18,19]$. The techniques used were aeration tube insertion alone for the first stage of retraction, or combined with resection of the retraction and grafting with cartilage or fascia, or only grafting. Patients with COM suppurativa underwent tympanoplasty wall up with antrotomy or mastoidectomy with tympanic perforation grafting [20]. Patients with cholesteatoma were treated with two stage tympanoplasty procedure. There were no positive data about allergy per anamnesis or clinical examination in the whole patient group. Samples of middle ear secretion were taken with sterile cotton swabs during surgery, and bacterial cultures were done immediately after sampling, inoculated to blood agar medium and MacConkey medium. The cultures were incubated for 24 hours at $35^{\circ} \mathrm{C}$, and bacteria were identified by Gram staining and biochemical tests. Standard biochemical measurements of blood parameters were performed for all patients. 


\section{Genetic analysis}

Genomic DNA was isolated from peripheral blood samples collected with ethylenediaminetetraacetic acid and purified by the proteinase K/phenol extraction method. The $+3953 \mathrm{C} / \mathrm{T}$ polymorphism in IL-1 $\beta$ gene and $86 \mathrm{bp} \mathrm{VNTR} \mathrm{polymorphism} \mathrm{in} \mathrm{the}$ IL-1RA gene were analyzed by the polymerase chain reaction method on an ABI 9700 Thermal Cycler (GeneAmp; Applied Biosystems, Foster City, CA, USA) in a $20 \mu \mathrm{L}$ reaction mixture containing $200 \mathrm{ng}$ of genomic DNA using the following primers: IL-1 $\beta$ (forward 5'-GTATATGCTCAGTGTCCTC-3' and reverse 5'-CATGGAGAATTAGCAAGCTG-3), IL1-RA (forward 5'-CTCAGCAACACTCCTAT-3' and reverse 5'-TCCTGGTCTGCAGGTAA-3). The genotypes for IL-1 $\beta+3953 \mathrm{C} / \mathrm{T}$, TaqI polymorphism were visualized on $8 \%$ polyacrylamide gel after overnight restriction digestion with TaqI enzyme and for IL-1RA 86 bpVNTR polymorphism on $1.8 \%$ agarose gel.

\section{Statistical analysis}

The frequencies of genotypes and alleles were determined by the gene counting method. To compare the obtained frequency distribution of genotypes in the control group with the expected values of the Hardy-Weinberg equilibrium, we applied the chisquare test. For test of independence between two categorical variables, the Pearson chi-square test was used. Multiple logistic regression analysis was performed in order to assess if IL-1 $\beta$ and IL-1RA polymorphisms are independently associated with susceptibility to COM (expressed in terms of adjusted odds ratio $[\mathrm{OR}]$ and its $95 \%$ confidence interval $[\mathrm{CI}])$. In all tests, the value of $P<0.05$ was considered significant. All statistical analyses were performed using Statistica software 5.0 (Statsoft Inc., Palo Alto, CA, USA). The statistical power of the study for the observed effect of polymorphism on susceptibility to COM was calculated using the power and sample size calculation (v3.0.43) [21].

\section{RESULTS}

\section{Genotypes and alleles in COM patients and controls}

The prevalence of VNTR IL-1RA and IL-1 $\beta$ TaqI genotypes and alleles in COM patients and controls were shown in Table 1. We didn't find the deviation from Hardy-Weinberg equilibrium in the investigated groups. Distribution of genotypes and alleles of IL-1 $\beta$ TaqI polymorphism were not significantly different in patients compared with the control group. The significant difference between patients and controls was observed for both, genotype and allele frequencies of IL-1RA VNTR polymorphism $(P<0.01)$ (Table 1). By univariate analysis we calculated crude OR for IL-1RA allele 2 containing genotypes (OR, 0.48; $95 \%$ CI, 0.29 to $0.78 ; P=0.003)$, the IL-1 TaqI 22 genotype (OR, 1.36 ; 95\% CI, 0.44 to $4.23 ; P=0.597)$, male sex (OR, $0.68 ; 95 \% \mathrm{CI}$, 0.41 to $1.10 ; P=0.114)$ and age (OR, $0.99 ; 95 \% \mathrm{CI}, 0.98$ to $1.01 ; P=0.473)$. We further found that IL-1RA allele 2 containing genotypes (OR, $0.47 ; 95 \% \mathrm{CI}, 0.29$ to $0.76 ; P=0.004$ ) had an independent favorable association with $\mathrm{COM}$, using multivariate logistic analysis that included polymorphisms (IL-1ßTaqI and IL-1RA VNTR genotypes grouped with regard to allele 2 presence or absence), age and sex (Table 2). We had the study power of $86 \%$ for the observed association with an $\mathrm{OR}=0.47$, at the significance level of 0.05 and the given sample size.

\section{Genotypes and alleles in COM patients without cholesteatoma and COM patients with cholesteatoma}

The prevalence of VNTR IL-1RA and IL-1 $\beta$ TaqI genotypes in COM patients without cholesteatoma and COM patients with cholesteatoma was not significantly different (Table 3). We found a significant difference in the IL-1RA VNTR allele frequency distribution between two groups of patients $(P=0.034)$ (Table 3$)$, with allele 1 predominance in COM patients without cholesteatoma and allele 2 predominance in COM patients with choles-

Table 1. Genotype and allele frequencies of the IL-1RA VNTR and IL-1 $\beta$ Taql gene polymorphisms in COM patients and controls

\begin{tabular}{|c|c|c|c|c|c|c|c|}
\hline \multirow{2}{*}{ Genotype } & \multirow{2}{*}{$\operatorname{COM}(n=189)$} & \multirow{2}{*}{ Control $(n=119)$} & \multirow{2}{*}{$P$-value ${ }^{\text {a) }}$} & \multicolumn{4}{|c|}{ Allele frequency } \\
\hline & & & & Allele & $\mathrm{COM}$ & Control & $P$-value \\
\hline IL-1RA VNTR & & & & & & & $<0.01$ \\
\hline 11 & $133(70.4)$ & $60(50.4)$ & & 1 & 0.81 & 0.71 & \\
\hline 12 & $38(20.1)$ & $40(33.6)$ & & 2 & 0.16 & 0.26 & 0.005 \\
\hline 13 & $5(2.7)$ & $8(6.7)$ & 0.006 & 3 & 0.03 & 0.03 & \\
\hline 22 & $10(5.3)$ & $11(9.3)$ & & & & & \\
\hline 23 & $1(0.5)$ & 0 & & & & & \\
\hline 33 & $2(1.0)$ & 0 & & & & & \\
\hline \multicolumn{8}{|l|}{ IL-1 $\beta$ TaqI } \\
\hline 11 & $110(58.2)$ & $61(51.3)$ & & 1 & 0.77 & 0.73 & 0.285 \\
\hline 12 & $70(37.1)$ & $51(42.8)$ & 0.487 & 2 & 0.23 & 0.27 & \\
\hline 22 & $9(4.7)$ & $7(5.9)$ & & & & & \\
\hline
\end{tabular}

Values are presented as number (\%).

IL-1RA, interleukin-1 receptor antagonist; VNTR, variable number tandem repeat; IL-1 $\beta$, interleukin-1 beta; COM, chronic otitis media.

a) $P$-value (chi-square) of the difference in genotype and allele frequency distribution. 
Table 2. Odds ratio for COM in regard to IL-1RA VNTR genotypes grouped by allel 2 status

\begin{tabular}{lcccccc}
\hline IL-1RA VNTR & COM & Control & Unadjusted OR $(95 \%$ Cl) & $P$-value & Adjusted OR $(95 \%$ Cl) & $P$-value \\
\hline Allele 2- & $140(74.1)$ & $68(57.1)$ & - & - & - & - \\
Allele 2+ & $49(25.9)$ & $51(42.9)$ & $0.48(0.29-0.78)$ & 0.003 & $0.47(0.29-0.76)$ & 0.004 \\
\hline
\end{tabular}

Values are presented as number (\%) unless otherwise indicated.

COM, chronic otitis media; IL-1RA, interleukin-1 receptor antagonist; VNTR, variable number tandem repeat; OR, odds ratio; Cl, confidence interval; IL-1ß, interleukin-1 beta.

a)Adjusted for sex, age and IL-1 $\beta$ Taql polymorphism.

Table 3. Genotype frequencies of the IL-1RA VNTR and IL-1 $\beta$ Taql gene polymorphisms in COM patients with and without cholesteatoma

\begin{tabular}{|c|c|c|c|c|c|c|c|}
\hline \multirow{2}{*}{ Genotype } & \multirow{2}{*}{$\begin{array}{l}\text { Without cholesteatoma } \\
\qquad(n=119)\end{array}$} & \multirow{2}{*}{$\begin{array}{l}\text { With cholesteatoma } \\
\qquad(\mathrm{n}=70)\end{array}$} & \multirow{2}{*}{$P$-value ${ }^{a)}$} & \multicolumn{4}{|c|}{ Allele frequency } \\
\hline & & & & Allele & Without cholesteatoma & With cholesteatoma & $P$-value ${ }^{a)}$ \\
\hline \multicolumn{8}{|c|}{ IL-1RA VNTR } \\
\hline 11 & $88(74.0)$ & $45(63.6)$ & & 1 & 0.85 & 0.76 & \\
\hline 12 & $25(21.0)$ & $13(18.2)$ & & 2 & 0.13 & 0.19 & 0.034 \\
\hline 13 & $1(0.8)$ & $4(5.4)$ & 0.211 & 3 & 0.02 & 0.05 & \\
\hline 22 & $4(3.4)$ & $6(9.9)$ & & & & & \\
\hline 23 & 0 & $1(1.8)$ & & & & & \\
\hline 33 & $1(0.8)$ & $1(1.8)$ & & & & & \\
\hline \multicolumn{8}{|l|}{ IL-1 $\beta$ TaqI } \\
\hline 11 & $66(55.5)$ & $45(64.3)$ & & 1 & 0.74 & 0.81 & 0.115 \\
\hline 12 & $45(37.8)$ & 24 (34.3) & 0.189 & 2 & 0.26 & 0.19 & \\
\hline 22 & $8(6.7)$ & $1(1.4)$ & & & & & \\
\hline
\end{tabular}

Values are presented as number (\%).

IL-1RA, interleukin-1 receptor antagonist; VNTR, variable number tandem repeat; IL-1 $\beta$, interleukin-1 beta; COM, chronic otitis media.

${ }^{a} P$-value (chi-square) of the difference in genotype and allele frequency distribution.

teatoma. Subgroups of COM patients, those without cholesteatoma and those with cholesteatoma had significantly decreased IL-1RA allele 2 containing genotypes in comparison to controls $(P=0.003$ and $P=0.021$, respectively), but there was no difference between two groups of patients (allele 2+: non-cholesteatoma vs. cholesteatoma, $24.4 \%$ vs. $28.6 \% ; P=0.560)$.

\section{DISCUSSION}

The aim of this study was to evaluate the association of the polymorphisms in two innate immunity/inflammation cascade genes from a single cluster (IL-1 $\beta+3953 \mathrm{C} / \mathrm{T}$, TaqI and IL-1RA $86 \mathrm{bp}$ VNTR) with COM with regard to cholesteatoma. Genes that control the production of cytokines are the first choice candidate genes for COM, same as for a variety of chronic inflammatory and autoimmune human diseases [22]. But up to date not many studies have been performed using a candidate gene approach for COM/ROM. The main finding of this study was that allele 2 of VNTR IL-1RA polymorphism was favorably associated with COM. Previously, only the Finnish study reported an association between IL-1 $\alpha$ and ROM in children without allergic disorders [14]. The lack of association between IL-1 $\beta$ +3953 C/T polymorphism with COM, in this study, is in agreement with previous results $[14,15]$. Moreover, previously we didn't find the association of this polymorphism with other chronic inflammatory disease, multiple sclerosis, in patients from Serbia [23]. Still, the association between acute OM symptom severity and IL-1 $\beta+3953$ polymorphism, in a subset of children with more severe tympanic membrane involvement, was found recently [24]. In this study, we have shown the significant favorable effect of IL1-RA VNTR allele 2 toward susceptibility to COM, adjusted for IL-1 $\beta$ TaqI polymorphism, age and sex. Previously the same polymorphism has not been associated with recurrent acute OM in Finnish population [14]. The IL-1RA allele 2 was suggested to be associated with higher IL-1RA levels $[17,25]$, which can lead to down-regulation of IL-1 mediated proinflammatory signaling pathways thus becoming the reasonable candidate gene in inflammatory diseases. It is known that complex formed by IL- 1 cytokines and receptors recruits intracellular signaling, including MyD88-dependent activation of NF$\kappa B, p 38$, JNK, and ERK [26]. Novel results showed that pathogens that causes pneumonia and OM, exert proinflammatory effects through the NF-kB pathway viaTLR2, MyD88, and IRAK4 [27]. The IL-1RA after binding to IL-1 receptor does not activate intracellular signaling pathways thus exerts anti-inflammatory role. It was recently shown that blockage of the IL-1 $/$ /PI3K/NF$\kappa B$ signaling pathway may be a major mechanism by which IL1RA inhibits proinflammatory effects [28]. Recent meta-analysis in chronic periodontitis suggested a decreased risk for aggressive periodontitis in allele 2 carriers in Caucasians and significantly higher risk for chronic periodontitis in Asians [29]. It has been 
already known that IL1-RA VNTR allele frequency may vary by ethnicity and previously the association of allele 2 with chronic rhinosinusitis was found in Taiwanese, but not in Caucasians [30]. In multiple sclerosis, another chronic inflammatory disease, allele 2 had been associated with a more benign form of disease in patients from Italy [31] and had a protective role for its susceptibility in Serbian population [23]. Although IL-1RA has been present in the research of inflammatory disease for more than a decade only recently, it was thoroughly described as an active counterpart of IL-1 $\beta$ actions, which diminishes deleterious effects on metabolic processes in downstream organs and tissue damage [32]. Hereof we investigated its copy number variant with regard to cholesteatoma in patients with $\mathrm{COM}$ and we show the significant difference in allele frequency, with allele 2 predominance in COM patients with cholesteatoma. Molecular mechanisms and genetic basis of both, COM and cholesteatoma and their potential clinical aggressiveness are challenging subject in current research [33] and has yet to be resolved. Recently, an extensive review was published in order to gather existing literature regarding heritability of cholesteatoma [34]. The heritable component of cholesteatoma etiology was suggested, although insufficiency in relevant literature suggests the need for a stronger body of evidence.

The major limitation of most of the genetic studies in COM, including this study was the limited number of cases included. This should be overcome in future studies and multicentric approach would be the most valuable. The more genetic data we gather along with clinical data, the more about the genetic architecture of COM will be visible. COM is a complex and multifactorial disease with both genetic and environmental factors underlying its pathophysiology. The drawback inherent from analyzing the limited number of factors, as in this study and most of the studies up to date, should be overcome too, and the multifactorial models of COM susceptibility and complications should be defined. Nevertheless, the retrospectively calculated study power for the significant association (86\%) suggests that current results should be taken into account for further research, primarily because the VNTRs, such as IL-1RA VNTR, were not investigated in the SNP genome wide association studies.

In conclusion, the carriers of allele 2 of VNTR IL-1RA polymorphism had a decreased risk for COM, which is in agreement with findings in other inflammatory disease and its previous association with higher IL-1RA levels. Possible down-regulation of IL-1 mediated proinflammatory signaling pathways via IL-1RA in COM as well as results of our study should be further investigated and replicated.

\section{CONFLICT OF INTEREST}

No potential conflict of interest relevant to this article was reported.

\section{ACKNOWLEDGMENTS}

This research was conducted as part of the OI 175085, financed by the Ministry of Education, Science and Technological Development of the Republic of Serbia.

\section{REFERENCES}

1. Smirnova MG, Kiselev SL, Gnuchev NV, Birchall JP, Pearson JP. Role of the pro-inflammatory cytokines tumor necrosis factor-alpha, interleukin- 1 beta, interleukin- 6 and interleukin- 8 in the pathogenesis of the otitis media with effusion. Eur Cytokine Netw. 2002 AprJun;13(2):161-72.

2. Daly KA, Brown WM, Segade F, Bowden DW, Keats BJ, Lindgren $\mathrm{BR}$, et al. Chronic and recurrent otitis media: a genome scan for susceptibility loci.Am J Hum Genet. 2004 Dec;75(6):988-97.

3. Segade F, Daly KA, Allred D, Hicks PJ, Cox M, Brown M, et al. Association of the FBXO11 gene with chronic otitis media with effusion and recurrent otitis media: the Minnesota COME/ROM Family Study. Arch Otolaryngol Head Neck Surg. 2006 Jul;132(7):729-33.

4. Allen EK, Chen WM, Weeks DE, Chen F, Hou X, Mattos JL, et al. A genome-wide association study of chronic otitis media with effusion and recurrent otitis media identifies a novel susceptibility locus on chromosome 2. J Assoc Res Otolaryngol. 2013 Dec;14(6):791-800.

5. Einarsdottir E, Hafren L, Leinonen E, Bhutta MF, Kentala E, Kere J, et al. Genome-wide association analysis reveals variants on chromosome 19 that contribute to childhood risk of chronic otitis media with effusion. Sci Rep. 2016 Sep;6:33240.

6. Dagan R, Leibovitz E, Leiberman A, Yagupsky P. Clinical significance of antibiotic resistance in acute otitis media and implication of antibiotic treatment on carriage and spread of resistant organisms. Pediatr Infect Dis J. 2000 May;19(5 Suppl):S57-65.

7. Liederman EM, Post JC, Aul JJ, Sirko DA, White GJ, Buchman CA, et al. Analysis of adult otitis media: polymerase chain reaction versus culture for bacteria and viruses. Ann Otol Rhinol Laryngol. 1998 Jan;107(1):10-6.

8. Kim H, Choo OS, Jang JH, Park HY, Choung YH. Chronological changes in microbial profiles in external and middle ear diseases: a 20-year study in Korea. Eur Arch Otorhinolaryngol. 2017 Mar;274(3): 1375-81.

9. Lindberg K, Rynnel-Dagoo B, Sundqvist KG. Cytokines in nasopharyngeal secretions; evidence for defective IL-1 beta production in children with recurrent episodes of acute otitis media. Clin Exp Immunol. 1994 Sep;97(3):396-402.

10. Sato K, Kawana M, Nonomura N, Nakano Y. Course of IL-1beta, IL6 , IL-8, and TNF-alpha in the middle ear fluid of the guinea pig otitis media model induced by nonviable Haemophilus influenzae. Ann Otol Rhinol Laryngol. 1999 Jun;108(6):559-63.

11. Sudhoff HH, Klenke C. Inflammation cascade related to biofilms in otitis media. In: Kania R, Ars B, editors. Biofilms in otitis. Amsterdam: Kugler Publications; 2015. p. 157-70.

12. Leichtle A, Klenke C, Ebmeyer J, Daerr M, Bruchhage KL, Hoffmann AS, et al. NOD-like receptor signaling in cholesteatoma. Biomed Res Int. 2015;2015:408169.

13. Klenke C, Janowski S, Borck D, Widera D, Ebmeyer J, Kalinowski J, et al. Identification of novel cholesteatoma-related gene expression signatures using full-genome microarrays. PLoS One. 2012;7(12): e52718.

14. Joki-Erkkila VP, Puhakka H, Hurme M. Cytokine gene polymorphism in recurrent acute otitis media. Arch Otolaryngol Head Neck 
Surg. 2002 Jan;128(1):17-20.

15. Patel JA, Nair S, Revai K, Grady J, Saeed K, Matalon R, et al. Association of proinflammatory cytokine gene polymorphisms with susceptibility to otitis media. Pediatrics. 2006 Dec;118(6):2273-9.

16. Pociot F, Molvig J, Wogensen L, Worsaae H, Nerup J. A TaqI polymorphism in the human interleukin-1 beta (IL-1 beta) gene correlates with IL-1 beta secretion in vitro. Eur J Clin Invest. 1992 Jun; 22(6):396-402.

17. Danis VA, Millington M, Hyland VJ, Grennan D. Cytokine production by normal human monocytes: inter-subject variation and relationship to an IL-1 receptor antagonist (IL-1Ra) gene polymorphism. Clin Exp Immunol. 1995 Feb;99(2):303-10.

18. Borgstein J, Gerritsma TV, Wieringa MH, Bruce IA. The Erasmus atelectasis classification: proposal of a new classification for atelectasis of the middle ear in children. Laryngoscope. 2007 Jul;117(7):1255-9.

19. Tos M. Upon the relationship between secretory otitis in childhood and chronic otitis and its sequelae in adults. J Laryngol Otol. 1981 Oct;95(10):1011-22.

20. Jesic SD, Dimitrijevic MV, Nesic VS, Jotic AD, Slijepcevic NA. Temporalis fascia graft perforation and retraction after tympanoplasty for chronic tubotympanic otitis and attic retraction pockets: factors associated with recurrence. Arch Otolaryngol Head Neck Surg. 2011 Feb;137(2):139-43.

21. DupontWD, PlummerWD Jr. Power and sample size calculations: a review and computer program. Control Clin Trials. 1990 Apr;11(2): 116-28.

22. Hollegaard MV, Bidwell JL. Cytokine gene polymorphism in human disease: on-line databases, Supplement 3. Genes Immun. 2006 Jun; 7(4):269-76.

23. Dincic E, Zivkovic M, Stankovic A, Obradovic D, Alavantic D, Kostic V, et al. Association of polymorphisms in CTLA-4, IL-1ra and IL1 beta genes with multiple sclerosis in Serbian population. J Neuroimmunol. 2006 Aug;177(1-2):146-50.

24. McCormick DP, Grady JJ, Diego A, Matalon R, Revai K, Patel JA, et al. Acute otitis media severity: association with cytokine gene polymorphisms and other risk factors. Int J Pediatr Otorhinolaryngol.
2011 May;75(5):708-12.

25. Schrijver HM, van As J, Crusius JB, Dijkstra CD, Uitdehaag BM. Interleukin (IL)-1 gene polymorphisms: relevance of disease severity associated alleles with IL-1beta and IL-1ra production in multiple sclerosis. Mediators Inflamm. 2003 Apr;12(2):89-94.

26. Palomo J, Dietrich D, Martin P, Palmer G, Gabay C. The interleukin (IL)-1 cytokine family: balance between agonists and antagonists in inflammatory diseases. Cytokine. 2015 Nov;76(1):25-37.

27. Wang Y, Wang Q, Li Y, Chen Y, Shao J, Nick N, et al. Mmm-derived lipid-associated membrane proteins activate IL-1 $\beta$ production through the NF-kB pathway via TLR2, MyD88, and IRAK4. Sci Rep. 2017 Jun;7(1):4349.

28. Ma J, Sun X, Guo T, Su H, Chen Q, Gong Z, et al. Interleukin-1 receptor antagonist inhibits angiogenesis via blockage IL-1 $\alpha / \mathrm{PI} 3 \mathrm{~K} / \mathrm{NF}-$ $\kappa \beta$ pathway in human colon cancer cell. Cancer Manag Res. 2017 Oct;9:481-93.

29. Ding C, Zhao L, Sun Y, Li L, Xu Y. Interleukin-1 receptor antagonist polymorphism (rs2234663) and periodontitis susceptibility: a metaanalysis. Arch Oral Biol. 2012 Jun;57(6):585-93.

30. Cheng YK, Lin CD, Chang WC, Hwang GY,Tsai SW, Wan L, et al. Increased prevalence of interleukin-1 receptor antagonist gene polymorphism in patients with chronic rhinosinusitis. Arch Otolaryngol Head Neck Surg. 2006 Mar;132(3):285-90.

31. Sciacca FL, Ferri C,Vandenbroeck K,Veglia F, Gobbi C, Martinelli F, et al. Relevance of interleukin 1 receptor antagonist intron 2 polymorphism in Italian MS patients. Neurology. 1999 Jun;52(9):1896-8.

32. Pedersen BK. Anti-inflammatory effects of exercise: role in diabetes and cardiovascular disease. Eur J Clin Invest. 2017 Aug;47(8):60011.

33. Hamed MA, Nakata S, Shiogama K, Suzuki K, Sayed RH, Nishimura Y, et al. Cytokeratin 13, cytokeratin 17, and Ki-67 expression in human acquired cholesteatoma and their correlation with its destructive capacity. Clin Exp Otorhinolaryngol. 2017 Sep;10(3):213-20.

34. Jennings BA, Prinsley P, Philpott C,Willis G, Bhutta MF. The genetics of cholesteatoma: a systematic review using narrative synthesis. Clin Otolaryngol. 2018 Feb;43(1):55-67. 